\title{
The Application of FIFA 11+ Injury Prevention Program on Youth Football Club in Semarang City
}

\author{
Sri Sumartiningsih ${ }^{1}$, Sugiharto ${ }^{2}$, Jens Eiberger ${ }^{3}$, Anggit Risdiyanto ${ }^{4}$, Ashril Yusof ${ }^{5}$ \\ \{ sri.sumartiningsih@mail.unnes.ac.id ${ }^{1}$, sgh@mail.unnes.ac.id ${ }^{2}$, \\ jenseiberger.sportscience@hotmail.com ${ }^{3}$ \} \\ Universitas Negeri Semarang, Semarang, Indonesia ${ }^{1,2,45}$ \\ Germany Fitness and Football Coach, Munich, Germany ${ }^{3}$
}

\begin{abstract}
To determine the effectiveness of FIFA 11+ kids as an injury prevention program in male youth football players. In addition, this study will evaluate the implementation of FIFA $11+$ as warming up and injury prevention for the youth football club. The quasi experimental and descriptive survey study design was conducted in this study. 24 football clubs in Semarang were observed and analyzed using interviews and questioner. From 24 football clubs, just 20 football clubs have kid's teams between the ages of 9 and 12 in January 2018-June 2020. The total youth athlete is 980 kids. The average time each warming up is 15-20 minutes. The rate of injury during a competition in each game base on how many athletes were injured was fifty. The coach age was sufficient for implementing the program - the coach's license was also an active variable for the success injury prevention program in their athletes.
\end{abstract}

Keywords: warming up, injury prevention, kids, football

\section{Introduction}

Football is the most popular sport worldwide [1]. The percentage risk of injury incidence at football during matches was higher than in training [2]. Lower limb and thigh strain was common injury location and dominant muscle injury during tournament and training session [3].

FIFA Marc makes protocol warming up called FIFA $11+$ to reduce injury percentage [4]. Various research found a positive effect of the FIFA 11+ program to the athletes [5][6][7][8]. The warming up program performed seven exercises for 15-20 minutes [9]. The exercises are focus on three exercises for unilateral and dynamic stability on the inferior extremity, three exercises for whole body strength and one exercises for falling technique [9].

The effectiveness of warming up the FIFA 11+ program was investigated. Numerous studies found that the FIFA 11+ reduced risk of injury inferior extremity, en- 
hanced performance, and physical attributes in football players [4][5][6][8][9][10]. The program positively useful reduce injury rate of $20-50 \%$ in football players [11][12]. In Indonesia, a limited study about injury prevention focus on implementing FIFA $11+$ in football clubs for youth football players. Therefore, this study aims to investigate the implementation of the FIFA 11+ warming up a program in Semarang football clubs for kids 9 to 12 years old.

\section{Methods}

A descriptive survey study design was conducted to assess the implementation of FIFA 11+ on Semarang city football clubs [13]. Twenty-four of football clubs in Semarang was recorded. The inclusion criteria were active football clubs and have a program for kids 9 to 12 years old, performed the training program minimum 2 times a week taken part as a participant in this study.

Before data collection, an online webinar meeting held to define the FIFA 11+ program, warming up exercise protocol to injury prevention in athletes. One of the researchers as speakers and explain the application to the coach, and the others supervised the coach training program on football club was used. The coach understand which is FIFA 11+ warming up program and usual warming they usually did.

Assessment for data collection, the coach asked to filled the questioner about the implementation of FIFA 11+ in youth football athletes. The warming up of FIFA 11+ exercise program was implemented during their coaching in 2018-2020.

The FIFA $11+$ is an extensive warm-up program with six running exercises at the starting and three exercises to activate the cardiovascular system at the finishing, and six specific preventive exercises especially on core and leg strength, balance and agility with three progressive levels for each exercise, as well as inferior extremity and trunk alignment cues, and it takes for 20-25 minutes' complete program [4][6][8][14].

Data were analyzed using the statistical package for the social sciences (SPSS) version 20. For data analysis to describe the descriptive implementation program FIFA $11+$ in Semarang city Football clubs. 


\section{$3 \quad$ Results and Discussions}

There were on percentage of the active football clubs and have a program for kids.

Table 1. Characteristic of Semarang city football clubs, $n=24$

\begin{tabular}{lc}
\hline \multicolumn{1}{c}{ Variable Category } & Percentage \\
\hline Active football club & $90 \%$ \\
Non active football club & $10 \%$ \\
have a training program for kids 9 to 12 years old & $83 \%$ \\
The training program for kids > 3 years & $83 \%$ \\
The training program for kids < 2 year & $17 \%$ \\
The club ever join the tournament in 2018-2020 & $87.5 \%$ \\
Followed the tournament $>6$ times/year & $62.5 \%$ \\
Followed the tournament 3-5 times/year & $30 \%$ \\
Followed the tournament <2 times/year & $8.5 \%$ \\
The exercise frequency (> 3 times/week) & $62.5 \%$ \\
The exercise frequency 2-3 times/week & $37.5 \%$ \\
The rate frequency of injury in each tournament $>4$ athletes & $50 \%$ \\
the rate frequency of injury each tournament 2-3 athletes & $35 \%$ \\
the rate frequency of injury each tournament $<2$ athletes & $15 \%$ \\
The duration of warm up program each training < 20 minutes & $50 \%$ \\
The duration of warm up program each training 10-20 minutes & $45 \%$ \\
The duration of warm up program each training < 10 minutes & $5 \%$ \\
The coach applied FIFA 11+ on warming up & $8.3 \%$ \\
The coach applied usual warming up & $91.7 \%$ \\
\hline
\end{tabular}

Table 2. The percentage Club with kids' football program $n=980$

\begin{tabular}{ll}
\hline Kids Age Program in Semarang Football club & Percentage \\
\hline 9 years & $24 \%$ \\
10 years & $29 \%$ \\
11 years & $24 \%$ \\
12 years & $22 \%$ \\
\hline
\end{tabular}

Table 3. The age percentage of the Coach Semarang city football club $n=80$

\begin{tabular}{ll}
\hline Age (year) & Percentage \\
\hline$<25$ & $20 \%$ \\
$25-35$ & $35 \%$ \\
$35-45$ & $35 \%$ \\
$>45$ & $10 \%$ \\
\hline
\end{tabular}


Table 4. The Football Coach License $n=80$

\begin{tabular}{ll}
\hline Name of License & Percentage \\
\hline No license & $13 \%$ \\
D & $67 \%$ \\
C AFC & $13 \%$ \\
B & $8 \%$ \\
A AFC & $0 \%$ \\
Pro AFC & $0 \%$ \\
\hline
\end{tabular}

This study aimed to investigate the implementation of the FIFA 11+ warm-up injury prevention program on Semarang city football clubs. The study found that only two clubs which applied the FIFA 11+ warm-up program for injury prevention. The average coach age who applied the FIFA $11+$ program was 24 years old.

Based on data collection found that the majority of Semarang football clubs have a program for kids. The dominant kid age was ten years old. In this age, they were followed tournament average seven times per year. Fifty percentage injury rate during the performance in the tournament. It is mean the coach not yet applied the FIFA 11+ warm-up injury prevention in training and before the competition.

The FIFA $11+$ program proved to reduce injury rates in youth, young, and adult football athletes $[4][5][9][10][12][15][16]$. The program also helps to enhance the strength and performance of football athletes [6][7][8][10]. The others advantage of FIFA $11+$ studied found that the warm-up protocol program increases the agility, dynamic balance, and flexibility [17][18][19][20].

The numerous study proved the effective FIFA 11+ warm-up injury prevention program. The proved study results were a reason the football clubs suggested to follow the program to reduce athletes from injury.

\section{Conclusion}

The football clubs which followed the FIFA 11+ warm-up program were minimum in Semarang city. The coach age was sufficient for implementing the program-the coach's license was also an active variable for the success injury prevention program in their athletes.

\section{Acknowledgements}

We would like to thank Faculty of Sports Science, Universitas Negeri Semarang, Indonesia for the funding. 


\section{References}

[1] Association FIdF. FIFA Big Count 2006: 270 million people active in football. FIFA Comunication Division. 2007.

[2] Ekstrand J, Hägglund M, Waldén M. Injury incidence and injury patterns in professional football: the UEFA injury study. British J. of Sports Med. 2011;45(7):553-8.

[3] Ekstrand J, Hägglund M, Waldén M. Epidemiology of muscle injuries in professional football (soccer). The American J. of Sports Med. 2011;39(6):1226-32.

[4] Bizzini M, Dvorak J. FIFA 11+: an effective programme to prevent football injuries in various player groups worldwide - a narrative review. British J. of Sports Med. 2015;49(9):577.

[5] Pomares-Noguera C, Ayala F, Robles-Palazón FJ, Alomoto-Burneo JF, LópezValenciano A, Elvira JLL, et al. Training Effects of the FIFA 11+ Kids on Physical Performance in Youth Football Players: A Randomized Control Trial. Frontiers in Pediatrics. 2018;6(40).

[6] Rössler R, Donath L, Bizzini M, Faude O. A new injury prevention programme for children's football - FIFA 11+ Kids - can improve motor performance: a cluster-randomised controlled trial. J. of Sports Scien. 2016;34(6):549-56.

[7] Zarei M, Namazi P, Abbasi H, Noruzyan M, Mahmoodzade S, Seifbarghi T. The Effect of Ten-Week FIFA 11+ Injury Prevention Program for Kids on Performance and Fitness of Adolescent Soccer Players. Asian J. Sports Med. 2018;9(3):e61013.

[8] Daneshjoo A, Rahnama N, Mokhtar AH, Yusof A. Effectiveness of injury prevention programs on developing quadriceps and hamstrings strength of young male professional soccer players. J. of Human Kine. 2013;39(1):115-25.

[9] Spurrier D. The 11+ Kids' warm-up program performed at least once a week reduces severe and lower extremity injuries in children playing football [commentary]. J. of Physio. 2019;65(1):53-.

[10] Daneshjoo A, Mokhtar AH, Rahnama N, Yusof A. The effects of injury preventive warmup programs on knee strength ratio in young male professional soccer players. PloS one. 2012;7(12)

[11] Comprehensive warm-up programme to prevent injuries in young female footballers: cluster randomised controlled trial. Bmj. 2008;337:a2469.

[12] Al Attar WSA, Soomro N, Pappas E, Sinclair PJ, Sanders RH. How effective are FMARC injury prevention programs for soccer players? A systematic review and metaanalysis. Sports medicine. 2016;46(2):205-17.

[13] Cowman S, Björkdahl A, Clarke E, Gethin G, Maguire J, Group EViPR. A descriptive survey study of violence management and priorities among psychiatric staff in mental health services, across seventeen european countries. BMC health services research. 2017;17(1):59.

[14] Akbari H, Sahebozamani M, Daneshjoo A, Amiri-Khorasani M. Effect of the FIFA 11+ programme on vertical jump performance in elite male youth soccer players. Montenegrin J. of Sports Scien. and Med. 2018;7(2):17.

[15] Silvers-Granelli H, Mandelbaum B, Adeniji O, Insler S, Bizzini M, Pohlig R, et al. Efficacy of the FIFA $11+$ injury prevention program in the collegiate male soccer player. The American J. of Sports Med. 2015;43(11):2628-37.

[16] Barengo NC, Meneses-Echávez JF, Ramírez-Vélez R, Cohen DD, Tovar G, Bautista JEC. The impact of the FIFA 11+ training program on injury prevention in football players: a systematic review. Int. J. of Environmental Res. and Pub. Healt. 2014;11(11):11986-2000.

[17] Cloak R, Nevill A, Smith J, Wyon M. The acute effects of vibration stimulus following FIFA $11+$ on agility and reactive strength in collegiate soccer players. J. of Sport and Health Scien. 2014;3(4):293-8. 
[18] Bizzini M, Impellizzeri FM, Dvorak J, Bortolan L, Schena F, Modena R, et al. Physiological and performance responses to the "FIFA 11+"(part 1): is it an appropriate warm-up? J. of Sports Scien. 2013;31(13):1481-90.

[19] Daneshjoo A, Mokhtar AH, Rahnama N, Yusof A. The effects of comprehensive warmup programs on proprioception, static and dynamic balance on male soccer players. PloS one. 2012;7(12):e51568.

[20] Ayala F, Pomares-Noguera C, Robles-Palazón FJ, del Pilar García-Vaquero M, RuizPérez I, Hernández-Sánchez S, et al. Training effects of the FIFA 11+ and harmoknee on several neuromuscular parameters of physical performance measures. Inter.J. of Sports Med. 2017;38(04):278-89. 